\title{
Protein Kinase A Regulates the Sensitivity of Spinal Commissural Axon Turning to Netrin-1 But Does Not Switch between Chemoattraction and Chemorepulsion
}

\author{
Simon W. Moore and Timothy E. Kennedy \\ Centre for Neuronal Survival, Montreal Neurological Institute, Department of Neurology and Neurosurgery, McGill University, Montreal, Quebec, Canada \\ H3A 2B4
}

\begin{abstract}
Bifunctional axon guidance cues have been grouped into two classes depending on whether changes in intracellular cAMP or cGMP switch the response of the growth cone between attraction and repulsion. According to this model, axons respond to netrin-1, a group I guidance cue, as a chemoattractant when cAMP levels are high in the growth cone but switch and are repelled when the intraneuronal concentration of cAMP is low. The model is complicated by the proposal that cAMP-dependent kinase, protein kinase A (PKA), functions as a downstream effector for several guidance cues, including netrin-1, suggesting a close inter-relationship between guidance cue signal transduction and mechanisms regulating the switch between attraction and repulsion. Here, we examine possible interactions between netrin-1-mediated axon guidance and cAMP signaling in embryonic rat spinal commissural neurons. We report that netrin-1 does not alter the concentration of cAMP or PKA activity in these neurons across a wide range of netrin-1 concentrations and time points after application, leading us to conclude that netrin-1 does not regulate PKA in these cells. In contrast to the cyclic nucleotide switch model, we report that, despite inhibiting PKA, embryonic spinal commissural axons were always attracted to netrin-1 and never repelled. Instead, manipulating PKA regulated the sensitivity of chemoattraction to netrin-1: PKA inhibition reduced, and PKA activation increased, the distance over which axons turn toward a source of netrin-1. These findings indicate that the mechanisms underlying cyclic nucleotideregulated switching are separable from the signal transduction mechanisms required for chemoattraction to netrin-1.
\end{abstract}

Key words: gradient; motility; chemotropism; cAMP; axon guidance; spinal cord

\section{Introduction}

During neural development, axons are directed to their targets by extracellular cues. Bifunctional guidance cues have been classified into one of two groups based on whether the response of the growth cone is converted between attraction and repulsion by changes in intracellular cAMP or cGMP (Song and Poo, 1999, 2001). According to this model, netrin-1 is a group I guidance cue: growth cones containing high levels of cAMP are attracted to netrin-1, whereas those with low cAMP levels are repelled (Ming et al., 1997). Netrin-1 has also been reported to signal by elevating intracellular cAMP (Hopker et al., 1999; Corset et al., 2000). Together, these findings have led to a model in which cAMP and protein kinase A (PKA) are downstream effectors of netrin-1 signaling, while also regulating the directionality of the axonal

\footnotetext{
Received Dec. 19, 2005; revised Jan. 13, 2006; accepted Jan. 18, 2006.

T.E.K. was supported by a Senior Bourses de Chercheurs-Boursiers Award from the Fonds de la Recherche en Santé du Québec. S.W.M. was supported by a Lloyd Carr-Harris Studentship, and the project was supported by the Canadian Institutes of Health Research. We thank Sonia Rodriques, Sathyanath Rajasekharan, Adriana Di Polo, and Phil Barker for comments on this manuscript.

Correspondence should be addressed to Timothy E. Kennedy, Center for Neuronal Survival, Montreal Neurological Institute, McGill University, 3801 University Avenue, Montreal, Quebec, Canada H3A 2B4. E-mail: timothy.kennedy@mcgill.ca.

DOl:10.1523/JNEUROSCI.5419-05.2006

Copyright $\odot 2006$ Society for Neuroscience $\quad$ 0270-6474/06/262419-05\$15.00/0
}

response to netrin-1 (Hopker et al., 1999; Song and Poo, 1999; Shewan et al., 2002; Nishiyama et al., 2003)

We tested this model of netrin-1 chemotropic function using embryonic rat spinal commissural neurons, cells that extend an axon to the floor plate at the ventral midline of the developing spinal cord. These axons are initially repelled by bone morphogenetic protein-7 (BMP7) and growth/differentiation factor-7 secreted by the roof plate at the dorsal midline (Augsburger et al., 1999; Butler and Dodd, 2003) and then attracted by netrin- 1 and sonic hedgehog secreted by the floor plate (Kennedy et al., 1994; Serafini et al., 1994; Charron et al., 2003). We reported previously that activating PKA recruits deleted in colorectal cancer (DCC) to the cell surface from an intracellular pool, enhancing axon extension in response to netrin-1 (Bouchard et al., 2004). This study provided evidence that inhibiting PKA slowed commissural axon extension to the floor plate but did not examine a role for PKA in commissural axon chemotropic turning to netrin-1. Here, we provide evidence that application of netrin-1 does not affect cAMP signaling in embryonic rat spinal commissural neurons across a wide range of netrin- 1 concentrations and time points. Furthermore, we demonstrate that PKA regulates the sensitivity of embryonic rat spinal commissural axon turning toward a source of netrin-1. Activating PKA increased the distance over which axons turned toward a source of netrin-1, whereas PKA inhibition reduced this distance. However, in contrast to the cy- 
clic nucleotide switch model, inhibiting PKA did not cause these axons to be repelled by netrin-1. We conclude that mechanisms underlying chemoattraction to netrin-1 are independent of mechanisms required for cyclic nucleotide-dependent switching. Our findings indicate that PKA regulates the sensitivity of spinal commissural axon chemoattraction to netrin-1 and are consistent with our previous report that PKA mobilizes DCC from an intracellular vesicular pool to the growth cone plasma membrane.

\section{Materials and Methods}

Reagents. Monoclonal anti-transient axonal glycoprotein-1 (Tag-1) (4D7) was obtained from the Developmental Studies Hybridoma Bank (University of Iowa, Iowa City, IA), and KT5720 [ $(9 R, 10 S, 12 S)$ 2,3,9,10,11,12-hexahydro-10-hydroxy-9-methyl-1-oxo-9,12-epoxy$1 \mathrm{H}$-diindolo[1,2,3-fg:3' $2^{\prime}, 1^{\prime}$-kl] pyrrolo[3,4-i] [1,6] benzodiazocine-10carboxylicacid hexyl ester] was obtained from Calbiochem (La Jolla, CA). Rabbit antibodies against cAMP response element-binding protein (CREB) and phosphorylated CREB (pCREB) (Ser133, 1B6) were obtained from Cell Signaling Technology (Beverly, MA). Forskolin (Fsk), DNase, and poly-D-lysine (PDL) $(70-150 \mathrm{kDa})$ were obtained from Sigma-Aldrich (Mississauga, Ontario, Canada). Neurobasal, heat-inactivated FBS (iFBS), B-27 supplement, GlutaMAX-1, penicillin-streptomycin, and $\mathrm{Ca}^{2+} / \mathrm{Mg}^{2+}$-free HBSS were purchased from Invitrogen (Burlington, Ontario, Canada). Recombinant netrin-1 protein was purified from a HEK293-EBNA cell line secreting netrin-1 as described previously (Serafini et al., 1994; Shirasaki et al., 1996).

Spinal commissural neuron cultures. Staged pregnant Sprague Dawley rats were obtained from Charles River Canada (St.-Constant, Quebec, Canada). The dorsal half of embryonic day 13 (E13) (vaginal plug, E0) rat spinal cords were isolated by microdissection and dissociated, as described previously (Placzek et al., 1990; Bouchard et al., 2004). In brief, dorsal spinal cords were incubated at $37^{\circ} \mathrm{C}$ for $30 \mathrm{~min}$ in $0.0002 \%$ DNase $\mathrm{Ca}^{2+} / \mathrm{Mg}^{2+}$-free HBSS. The tissue was then triturated with flamed glass pipettes to yield a suspension of single cells. For both cAMP ELISAs and pCREB Western blots, 2 million dissociated cells were plated and cultured in $35 \mathrm{~mm}$ tissue culture dishes (Corning, Corning, NY) previously coated with $20 \mu \mathrm{g} / \mathrm{ml}$ PDL for $2 \mathrm{~h}$ at room temperature. For the first $12 \mathrm{~h}$, cells were cultured in Neurobasal supplemented with 10\% iFBS, $2 \mathrm{~mm}$ GlutaMAX-1, $100 \mathrm{U} / \mathrm{ml}$ penicillin, and $100 \mu \mathrm{g} / \mathrm{ml}$ streptomycin. The medium was then changed to Neurobasal supplemented with $2 \%$ B-27, 2 mM GlutaMAX-1, $100 \mathrm{U} / \mathrm{ml}$ penicillin, and $100 \mu \mathrm{g} / \mathrm{ml}$ streptomycin for an additional $28 \mathrm{~h}$ before cell lysis. More than $90 \%$ of the cells in these cultures express Tag-1 and DCC, markers of commissural neurons in the dorsal spinal cord. Furthermore, choline acetyltransferase, expressed by motoneurons, was not detected in these cultures (Bouchard et al., 2004).

cAMP ELISA. After treatments, commissural neuron cultures were lysed, and the cAMP levels measured using a low pH cAMP ELISA (R \& D Systems, Minneapolis, MN) as per the instructions of the manufacturer for acetylated lysates. Absorbance in each well was measured on a model 680 microplate reader (Bio-Rad, Hercules, CA). Concentrations of each condition were normalized across experiments by determining percentage changes relative to the average value of controls, in the absence of netrin-1.

pCREB analysis. After treatments, cells were lysed in radioimmunoprecipitation assay/Laemmli buffer (60 mM Tris, $\mathrm{pH} 6.8,5 \%$ glycerol, 2.5\% SDS, $1.25 \%$ BME, 7.25\% DTT, $1 \%$ NP- $40,0.5 \%$ deoxycholate, and $150 \mathrm{~mm} \mathrm{NaCl}$ ). The relative amounts of unphosphorylated and phosphorylated CREB in lysates were assessed by Western blot analysis (Harlow and Lane, 1999). Films were exposed using chemiluminescence (PerkinElmer, Montreal, Quebec, Canada) and scanned on a ScanJet 5300C (Hewlett-Packard, Mississauga, Ontario, Canada). Intensities of each band were measured using Photoshop 7.0 (Adobe Systems, San Jose, $\mathrm{CA}$ ). Intensities across experiments were compared as percentage change in intensity relative to controls, without netrin-1.

Commissural axon turning assays. Segments of E11 rat spinal cord (vaginal plug, E0) were dissected, and aggregates of netrin-expressing HEK293-EBNA cells were prepared, as described previously (Placzek et al., 1990; Kennedy et al., 1994; Shirasaki et al., 1996). Cell aggregates were immobilized in collagen alongside dissected E11 spinal cords. The explanted tissue was cultured for $40 \mathrm{~h}$ in supplemented Neurobasal $(10 \%$ iFBS, $2 \mathrm{~mm}$ GlutaMAX-1, $100 \mathrm{U} / \mathrm{ml}$ penicillin, and $100 \mu \mathrm{g} / \mathrm{ml}$ streptomycin) and then fixed with $4 \%$ paraformaldehyde. The trajectories of commissural axons were fluorescently labeled with Tag-1 (4D7) antibodies, followed by an Alexa Fluor 546-coupled secondary against mouse IgM. Digital images were acquired using a Magnafire CCD camera (Optronics, Goleta, CA) on an Axiovert microscope (Zeiss, Toronto, Ontario, Canada). Images were printed, and the deflection distances were determined by an observer blind to the experimental conditions. Distances were compared across experiments as the percentage distance in each condition relative to the average value of controls. Statistical significance was evaluated by a one-way ANOVA with Sheffé's post hoc test (Systat 9; Systat, Point Richmond, CA).

E13 spinal cord dorsal explant cultures. Dorsal spinal cord explants were dissected from E13 rat embryos, as described previously (Tessier-Lavigne et al., 1988). Explants were embedded and cultured for $14 \mathrm{~h}$ in Neurobasal supplemented with $10 \%$ iFBS, $2 \mathrm{~mm}$ glutamine, $100 \mathrm{U} / \mathrm{ml}$ penicillin, and $100 \mu \mathrm{g} / \mathrm{ml}$ streptomycin. Digital images of Tag-1-positive commissural axons were acquired as described above.

\section{Results}

Netrin-1 does not regulate cAMP concentration or PKA activity in embryonic rat spinal commissural neurons

Elevation of cAMP results in PKA-dependent phosphorylation of CREB on Ser133 (Gonzalez and Montminy, 1989). Based on cAMP immunocytochemistry and pCREB analysis, we reported previously that netrin-1 does not affect cAMP-PKA signaling after netrin-1 application (Bouchard et al., 2004). We have now extended these findings, performing cAMP ELISAs and pCREB Western blot analyses across a wide range of time points and netrin- 1 concentrations. Application of $200 \mathrm{ng} / \mathrm{ml}$ netrin- 1 generates maximal commissural axon outgrowth from explants of E13 dorsal spinal cord, whereas $50 \mathrm{ng} / \mathrm{ml}$ generates approximately half-maximal outgrowth. Although these concentrations of netrin-1 elicited substantial commissural axon outgrowth (Fig. $1 A$ ), in no case did we find that they altered the concentration of cAMP or activation of PKA. Specifically, no significant difference in cAMP (Fig. $1 B$ ) or pCREB (Fig. $1 C$ ) was observed after 15 min of 50,100 , or $200 \mathrm{ng} / \mathrm{ml}$ netrin-1 stimulation. Furthermore, 200 $\mathrm{ng} / \mathrm{ml}$ netrin- 1 also failed to increase cAMP (Fig. $1 D$ ) or pCREB (Fig. $1 E$ ) after 5,15 , or $30 \mathrm{~min}$. In contrast, large increases in intracellular cAMP and pCREB were detected within 5 min of application of the adenylate cyclase agonist forskolin (10 $\mu \mathrm{M}$ Fsk) (Fig. $1 B-E$ ) (Metzger and Lindner, 1981).

\section{Inhibiting PKA reduces commissural axon sensitivity to netrin-1 but does not switch attraction to repulsion}

An aggregate of netrin-1-expressing cells placed against the cut edge of an E11 spinal cord explant causes embryonic spinal commissural axons to deviate from their dorsoventral trajectory and turn toward the source of netrin-1 (Fig. 2A,D) (Kennedy et al., 1994). Similarly, placing an explant of roof plate or BMPexpressing cells causes these axons to be repelled (Fig. 2 F) (Augsburger et al., 1999; Butler and Dodd, 2003). Given that commissural axons have the capacity to be either attracted or repelled, we used this turning assay to test the hypothesis that inhibiting PKA will switch the response of spinal commissural neurons to netrin-1 from attraction to repulsion. We found that application of 4 or $10 \mu \mathrm{M}$ KT5720, an inhibitor of PKA (Kase et al., 1987), generated a dramatic reduction in pCREB after $12 \mathrm{~h}$ in culture (Fig. 3). This effect is consistent with the reported $3.3 \mu \mathrm{M} \mathrm{IC}{ }_{50}$ of KT5720 for PKA at physiological ATP concentrations (Davies et al., 2000). Although KT5720 may influence targets other than 

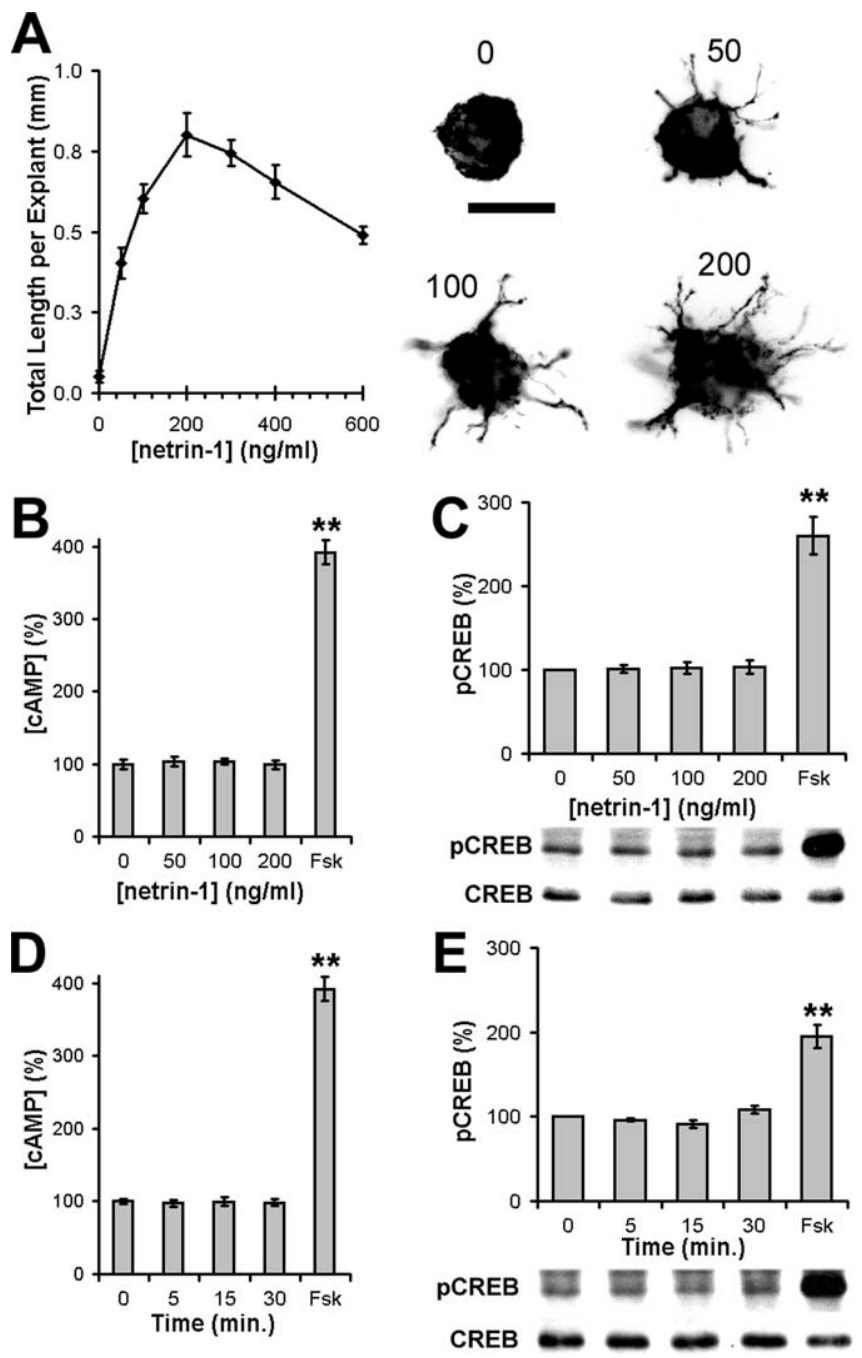

Figure 1. Netrin-1 does not alter CAMP levels or PKA activity in rat spinal commissural neurons. Netrin-1 induces the outgrowth of Tag-1-positive commissural neurons from dorsal spinal cord explants when present at concentrations between 50 and $200 \mathrm{ng} / \mathrm{ml}$ after $14 \mathrm{~h}$ in culture (A) (Serafini et al., 1994). The numbers above each explant indicate the concentration of netrin in nanograms per milliliter. In lysates of commissural neurons cultured for $40 \mathrm{~h}$, concentrations of CAMP and PKA activities were measured using CAMP ELISAs $(\boldsymbol{B}, \boldsymbol{D})$ and PCREB Western blots $(\boldsymbol{C}, \boldsymbol{E})$, respectively. The same concentrations of netrin-1 that induced extensive outgrowth failed to increase cAMP levels $(\boldsymbol{B})$ or PKA activity $(\boldsymbol{C})$ after $15 \mathrm{~min}$. Furthermore, $200 \mathrm{ng} / \mathrm{ml}$ netrin-1 failed to increase cAMP levels $(\boldsymbol{D})$ or PKA activity $(\boldsymbol{E})$ after 5,15 , or $30 \mathrm{~min}$. However, 5 min of Fsk increased cAMP levels $\left(n=4 ;{ }^{* *} p<0.01 ; \boldsymbol{B}, \boldsymbol{D}\right)$ and PKA activity $\left(n=3 ;{ }^{* *} p<0.01\right.$; $\boldsymbol{C}, \boldsymbol{E}$ ). In histograms $\boldsymbol{B}$ and $\boldsymbol{C}$, values are expressed as a percentage of $0 \mathrm{ng} / \mathrm{ml}$ netrin- $1 \pm \mathrm{SEM}$ and, in $\boldsymbol{D}$ and $\boldsymbol{E}$, are expressed as a percentage of time $0 \pm$ SEM. Scale bar, $100 \mu \mathrm{m}$.

PKA, we conclude that KT5720 inhibits PKA at the concentrations used. However, despite inhibiting PKA, commissural axons continued to be attracted to netrin-1. Although repellent turning was never observed, $10 \mu \mathrm{M}$ KT5720 reduced by $26 \%$ the distance over which rat commissural neuron axons turned toward the ectopic source of netrin-1 ( $n=27 ; p<0.01)$ (Fig. $2 B-D)$.

\section{Increasing cAMP concentration and activating PKA increases} the sensitivity of commissural axon turning to netrin-1

We reported previously that activating PKA recruits DCC from an intracellular vesicular pool to the plasma membrane of embryonic rat spinal commissural neurons and that this increases axon extension in response to netrin-1 (Bouchard et al., 2004). These findings led us to hypothesize that activating PKA will enhance the sensitivity of commissural neurons to a gradient of netrin-1, increasing the distance over which chemoattractive turning occurs. In contrast to this prediction, cAMP and PKA have been reported not to alter the sensitivity of cultured Xenopus spinal neurons as they turn in response to netrin-1 (Ming et al., 1997). We therefore tested our hypothesis using the embryonic rat spinal commissural axon turning assay described above. Elevation of cAMP by application of $10 \mu \mathrm{M}$ forskolin (Fig. $1 B-E$ ) significantly increased the range over which axons turn toward a source of netrin-1 $(n=60 ; p<0.025)$ (Fig. $2 C-E)$. This is consistent with our previous report that PKA activation recruits DCC to the growth cone plasma membrane (Bouchard et al., 2004).

\section{Discussion}

Here we examined the interaction of netrin-1 and cAMP-PKA signaling in embryonic rat spinal commissural neurons. Application of netrin-1 evoked no significant change in either the concentration of cAMP or the activity of PKA across a wide range of time points and netrin concentrations. Furthermore, despite inhibiting PKA, commissural axons did not switch their response to netrin-1. Rather, inhibiting PKA reduced, and activating PKA increased, the distance over which commissural axons turn toward a source of netrin-1. We conclude that activating PKA is not required for spinal commissural axon chemoattraction to netrin- 1 and that mechanisms underlying netrin- 1 chemoattraction are separable from mechanisms required for cyclic nucleotide-regulated switching. Consistent with PKA recruiting DCC to the growth cone plasma membrane from an intracellular vesicular pool (Bouchard et al., 2004), our findings indicate that cAMP and PKA regulate the sensitivity of spinal commissural axon chemoattractive turning toward netrin-1 (for the model, see supplemental Fig. 1, available at www.jneurosci.org as supplemental material).

The absence of a cAMP-mediated switch between attraction and repulsion contrasts with findings obtained using cultured Xenopus retinal ganglion cells (RGCs) or Xenopus spinal neurons, whose axons are either attracted or repelled by netrin-1 depending on the intraneuronal concentration of cAMP (Ming et al., 1997; Song et al., 1997, 1998; Hopker et al., 1999). Attraction to a source of netrin-1 requires DCC, whereas members of the Unc5 homolog netrin receptor family (Unc5A-Unc5D) are required for the repellent response (for review, see Huber et al., 2003). It is not clear which netrin-1 receptors are expressed by the Xenopus spinal neurons assayed in vitro, and the heterogeneous mixture of cells in these cultures confounds biochemical analyses. RGCs have been shown to express both DCC and multiple Unc5 homologs in zebrafish, rats, and mice (Deiner et al., 1997; Petrausch et al., 2000; Ellezam et al., 2001). Xenopus RGCs express DCC (de la Torre et al., 1997; Shewan et al., 2002), and, although the single identified Xenopus Unc5 homolog is not expressed by RGCs (Anderson and Holt, 2002), it seems likely that they express a different family member. Two reports suggest that the relative amounts of DCC and Unc5 homologs expressed dictates whether an axon responds to netrin- 1 as an attractant or repellent (Hamelin et al., 1993; Hong et al., 1999). In Caenorhabditis elegans, ectopic expression of Unc5 caused axons to be repelled rather than attracted to a source of the netrin Unc6 (Hamelin et al., 1993). Similarly, growth cones of cultured Xenopus spinal neurons were repelled by netrin-1 when they were engineered to overexpress Unc5 (Hong et al., 1999). Interestingly, recent findings indicate that the cell surface presentation of DCC and Unc5 homolog netrin receptors is regulated by PKA and PKC, respec- 
tively (Williams et al., 2003; Bouchard et al., 2004). These, and our current findings, support an emerging model in which kinase activity regulates the amounts of DCC and Unc5 homologs inserted into the growth cone plasma membrane, which in turn determines whether the axonal response to netrin-1 promotes or inhibits outgrowth. Embryonic rat spinal commissural neurons, however, do not express Unc5 homologs as they are extending to the floor plate (Leonardo et al., 1997). The responses observed therefore reflect DCC function in the absence of Unc5 homologs. Thus, the difference in the response to netrin-1 found between embryonic rat spinal commissural neurons and Xenopus spinal and retinal neurons may be attributable to differences in the netrin receptors expressed by these cells.

PKA is often included as a downstream component of netrin-1 chemoattractive signaling (Song and Poo, 1999; Nishiyama et al., 2003), but little direct evidence supports this conclusion. A modest increase in cAMP immunoreactivity was reported in Xenopus RGC growth cones after exposure to netrin-1 (Hopker et al., 1999), but biochemical analyses to support this finding have not been performed. The adenosine $2 \mathrm{~b}$ receptor (A2b), a G-protein-coupled receptor that generates an increase in cAMP when bound to adenosine (Ralevic and Burnstock, 1998), has been proposed to function as a receptor for netrin-1 in embryonic rat commissural neurons (Corset et al., 2000). In contrast, subsequent studies demonstrated that embryonic rat commissural neurons do not express A2b as they extend axons to the floor plate, and pharmacological manipulations of adenosine receptor activity did not affect axon outgrowth or turning in response to netrin-1 (Stein et al., 2001; Bouchard et al., 2004). It has been shown that manipulating A2b activity in Xenopus RGCs alters the concentration of cytosolic cAMP and switches between attractant and repellent responses to netrin-1 (Shewan et al., 2002), but these experiments did not provide evidence that netrin- 1 itself signals through A2b. Our finding that netrin-1 does not regulate the cytosolic cAMP concentration in commissural neurons reinforces the conclusion that $\mathrm{A} 2 \mathrm{~b}$ is not a receptor for netrin-1 in these cells.

Although PKA is not activated downstream of netrin-1 and DCC in commissural neurons, we do not rule out that other cues encountered by a migrating commissural growth cone may influence attraction to netrin-1 by regulating PKA. For example, laminin-1 has been reported to switch netrin-1 from an attractant to a repellent of RGC axon outgrowth by reducing cAMP (Hopker et al., 1999). Furthermore, inhibiting PKA reduced spinal commissural axon extension to the floor plate (Bouchard et al., 2004), consistent with the action of an as yet unidentified endogenous activator of PKA in the neuroepithelium of the embryonic rat spinal cord.

Our findings indicate that the capacity of cAMP-PKA signaling to switch between chemoattraction and chemorepulsion is not ubiquitous to all cells that respond to netrin-1. We conclude that netrin-1 does not activate cAMP-PKA signaling in embryonic rat spinal commissural neurons, that PKA activation is not
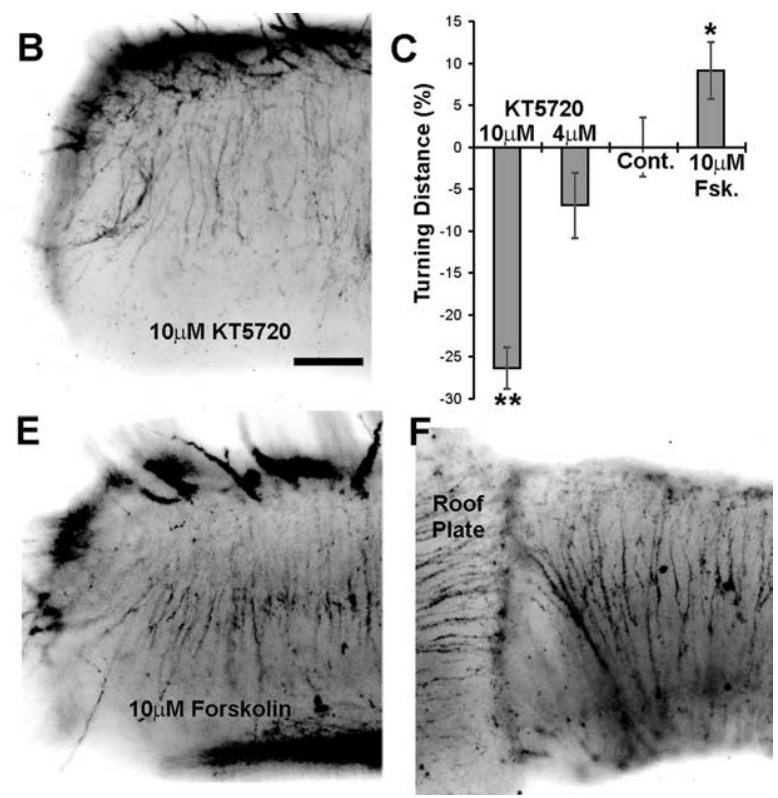

Figure 2. CAMP and PKA regulate the range over which axons turn toward netrin-1. Aggregates of netrin-1-expressing HEK293-EBNA cells were cultured alongside explants of E11 rat spinal cord, as shown in $A$. Explants were cultured for $40 \mathrm{~h}$ in the distance relative to the absence of drugs. KT5720 at $10 \mu \mathrm{m}$ resulted in a $26.3 \%$ reduction $\left(n=27 ;{ }^{* *} p<0.01\right)$ of the turning observed to a netrin-1 source, despite the ability of the commissural axon to be repelled by roof plate, as described previously $(\boldsymbol{F})$ (Augsburger et al., 1999). Scale bar, $100 \mu \mathrm{m}$.

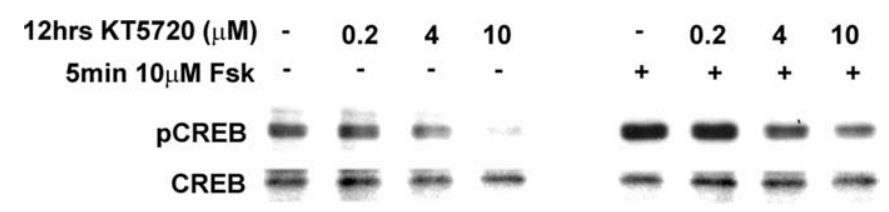

Figure 3. KT5720 inhibits PKA activity in rat spinal commissural neurons. KT5720 is an ATP analog that competitively inhibits PKA (Kase et al., 1987). After $24 \mathrm{~h}$ in culture, E13 spinal commissural neurons were then cultured for an additional $12 \mathrm{~h}$ with KT5720. As indicated, some cultures were then lysed immediately, whereas others were stimulated with $10 \mu \mathrm{m}$ forskolin for 5 min before lysis.

required for chemoattraction to netrin-1, and that mechanisms underlying chemoattraction to netrin-1 are independent of mechanisms required for cyclic nucleotide-dependent switching.

\section{References}

Anderson RB, Holt CE (2002) Expression of UNC-5 in the developing $X e$ nopus visual system. Mech Dev 118:157-160.

Augsburger A, Schuchardt A, Hoskins S, Dodd J, Butler S (1999) BMPs as mediators of roof plate repulsion of commissural neurons. Neuron 24:127-141.

Bouchard JF, Moore SW, Tritsch NX, Roux PP, Shekarabi M, Barker PA, Kennedy TE (2004) Protein kinase A activation promotes plasma membrane insertion of DCC from an intracellular pool: a novel mechanism regulating commissural axon extension. J Neurosci 24:3040-3050.

Butler SJ, Dodd J (2003) A role for BMP heterodimers in roof platemediated repulsion of commissural axons. Neuron 38:389-401.

Charron F, Stein E, Jeong J, McMahon AP, Tessier-Lavigne M (2003) The morphogen sonic hedgehog is an axonal chemoattractant that collaborates with netrin-1 in midline axon guidance. Cell 113:11-23.

Corset V, Nguyen-Ba-Charvet KT, Forcet C, Moyse E, Chedotal A, Mehlen P (2000) Netrin-1-mediated axon outgrowth and cAMP production requires interaction with adenosine A2b receptor. Nature 407:747-750.

Davies SP, Reddy H, Caivano M, Cohen P (2000) Specificity and mecha- 
nism of action of some commonly used protein kinase inhibitors. Biochem J 351:95-105.

Deiner MS, Kennedy TE, Fazeli A, Serafini T, Tessier-Lavigne M, Sretavan DW (1997) Netrin-1 and DCC mediate axon guidance locally at the optic disc: loss of function leads to optic nerve hypoplasia. Neuron 19:575-589.

de la Torre JR, Hopker VH, Ming GL, Poo MM, Tessier-Lavigne M, Hemmati-Brivanlou A, Holt CE (1997) Turning of retinal growth cones in a netrin-1 gradient mediated by the netrin receptor DCC. Neuron 19:1211-1224.

Ellezam B, Selles-Navarro I, Manitt C, Kennedy TE, McKerracher L (2001) Expression of netrin-1 and its receptors DCC and UNC-5H2 after axotomy and during regeneration of adult rat retinal ganglion cells. Exp Neurol 168:105-115.

Gonzalez GA, Montminy MR (1989) Cyclic AMP stimulates somatostatin gene transcription by phosphorylation of CREB at serine 133. Cell 59:675-680.

Hamelin M, Zhou Y, Su MW, Scott IM, Culotti JG (1993) Expression of the UNC-5 guidance receptor in the touch neurons of $C$. elegans steers their axons dorsally. Nature 364:327-330.

Harlow E, Lane D (1999) Using antibodies a laboratory manual. Cold Spring Harbor, NY: Cold Spring Harbor Laboratory.

Hong K, Hinck L, Nishiyama M, Poo MM, Tessier-Lavigne M, Stein E (1999) A ligand-gated association between cytoplasmic domains of UNC5 and DCC family receptors converts netrin-induced growth cone attraction to repulsion. Cell 97:927-941.

Hopker VH, Shewan D, Tessier-Lavigne M, Poo M, Holt C (1999) Growthcone attraction to netrin-1 is converted to repulsion by laminin-1. Nature 401:69-73.

Huber AB, Kolodkin AL, Ginty DD, Cloutier JF (2003) Signaling at the growth cone: ligand-receptor complexes and the control of axon growth and guidance. Annu Rev Neurosci 26:509-563.

Kase H, Iwahashi K, Nakanishi S, Matsuda Y, Yamada K, Takahashi M, Murakata C, Sato A, Kaneko M (1987) K-252 compounds, novel and potent inhibitors of protein kinase $\mathrm{C}$ and cyclic nucleotide-dependent protein kinases. Biochem Biophys Res Commun 142:436-440.

Kennedy TE, Serafini T, de la Torre JR, Tessier-Lavigne M (1994) Netrins are diffusible chemotropic factors for commissural axons in the embryonic spinal cord. Cell 78:425-435.

Leonardo ED, Hinck L, Masu M, Keino-Masu K, Ackerman SL, TessierLavigne M (1997) Vertebrate homologues of C. elegans UNC-5 are candidate netrin receptors. Nature 386:833-838.

Metzger H, Lindner E (1981) The positive inotropic-acting forskolin, a potent adenylate cyclase activator. Arzneimittelforschung 31:1248-1250.
Ming GL, Song HJ, Berninger B, Holt CE, Tessier-Lavigne M, Poo MM (1997) cAMP-dependent growth cone guidance by netrin-1. Neuron 19:1225-1235.

Nishiyama M, Hoshino A, Tsai L, Henley JR, Goshima Y, Tessier-Lavigne M, Poo MM, Hong K (2003) Cyclic AMP/GMP-dependent modulation of $\mathrm{Ca}^{2+}$ channels sets the polarity of nerve growth-cone turning. Nature 423:990-995.

Petrausch B, Jung M, Leppert CA, Stuermer CA (2000) Lesion-induced regulation of netrin receptors and modification of netrin-1 expression in the retina of fish and grafted rats. Mol Cell Neurosci 16:350-364.

Placzek M, Tessier-Lavigne M, Jessell T, Dodd J (1990) Orientation of commissural axons in vitro in response to a floor plate-derived chemoattractant. Development 110:19-30.

Ralevic V, Burnstock G (1998) Receptors for purines and pyrimidines. Pharmacol Rev 50:413-492.

Serafini T, Kennedy TE, Galko MJ, Mirzayan C, Jessell TM, Tessier-Lavigne M (1994) The netrins define a family of axon outgrowth-promoting proteins homologous to C. elegans UNC-6. Cell 78:409-424.

Shewan D, Dwivedy A, Anderson R, Holt CE (2002) Age-related changes underlie switch in netrin-1 responsiveness as growth cones advance along visual pathway. Nat Neurosci 5:955-962.

Shirasaki R, Mirzayan C, Tessier-Lavigne M, Murakami F (1996) Guidance of circumferentially growing axons by netrin-dependent and -independent floor plate chemotropism in the vertebrate brain. Neuron 17:1079-1088.

Song H, Poo M (2001) The cell biology of neuronal navigation. Nat Cell Biol 3:E81-E88.

Song H, Ming G, He Z, Lehmann M, McKerracher L, Tessier-Lavigne M, Poo M (1998) Conversion of neuronal growth cone responses from repulsion to attraction by cyclic nucleotides. Science 281:1515-1518.

Song HJ, Poo MM (1999) Signal transduction underlying growth cone guidance by diffusible factors. Curr Opin Neurobiol 9:355-363.

Song HJ, Ming GL, Poo MM (1997) cAMP-induced switching in turning direction of nerve growth cones. Nature 388:275-279.

Stein E, Zou Y, Poo M, Tessier-Lavigne M (2001) Binding of DCC by netrin-1 to mediate axon guidance independent of adenosine A2B receptor activation. Science 291:1976-1982.

Tessier-Lavigne M, Placzek M, Lumsden AG, Dodd J, Jessell TM (1988) Chemotropic guidance of developing axons in the mammalian central nervous system. Nature 336:775-778.

Williams ME, Wu SC, McKenna WL, Hinck L (2003) Surface expression of the netrin receptor $\mathrm{UNC5} \mathrm{H} 1$ is regulated through a protein kinase C-interacting protein/protein kinase-dependent mechanism. J Neurosci 23:11279-11288. 